\title{
Suppressive effect of oestradiol on chemical hepatocarcinogenesis in rats
}

\author{
I Shimizu, M Yasuda, Y Mizobuchi, Y-R Ma, F Liu, M Shiba, T Horie, S Ito
}

\begin{abstract}
Aims-To examine the effects of oestradiol and testosterone on the early carcinogenic changes expressed in rat liver from the diethylnitrosamine (DEN), 2-acetylaminofluorene (AAF), partial hepatectomy (PH) model of hepatocarcinogenesis.

Methods-Preneoplastic liver lesions were evaluated using immunohistochemical analysis of glutathione-S-transferase placental form (GST-P) expression; oestrogen and androgen receptor levels were measured by radioimmunoassay.

Results-Oestradiol administration to non-castrated DEN-AAF-PH treated males resulted in a decrease in the area of GST-P positive foci, while testosterone increased the serum oestradiol level and reduced the area. In males, castration alone and castration with oestradiol replacement significantly reduced the GST-P positive area, and increased the hepatic oestrogen receptor level. In DENAAF-PH treated females, castration with testosterone replacement was associated with a significant increase in the GST-P positive area and the hepatic androgen receptor level.

Conclusion-These findings suggest that exogenous and endogenous oestradiol can suppress chemical hepatocarcinogenesis. It appears that oestrogen receptors may be involved in the inhibition of malignant transformation of preneoplastic liver cells, while androgens and androgen receptors are involved in hepatocarcinogenesis.

(Gut 1998;42:112-119)
\end{abstract}

Keywords: hormone receptor; testosterone; diethylnitrosamine; glutathione-S-transferase placental form; antioxidant

Second Department of Internal Medicine, Tokushima University School of Medicine, Kuramoto-cho, Tokushima 770, Japan

I Shimizu

M Yasuda

Y Mizobuchi

Y-R Ma

F Liu

M Shiba

T Horie

$S$ Ito

Correspondence to: Dr Shimizu.

Accepted for publication 5 September 1997
Androgens have been implicated in associated with the development of HCC in patients with Fanconi's anaemia ${ }^{6}$ and aplastic anaemia. ${ }^{7}$ In rat studies, testosterone appears to be a growth factor for Morris hepatoma $7787 .{ }^{8}$ These findings suggest that androgens may be implicated in the aetiology of HCC, and that oestrogens may have a suppressive role in the development of human liver cancer. However, oral contraceptive agents are reported as hyperplastic agents in liver and are thought to be implicated in the development of hepatic adenoma and focal nodular hyperplasia in both sexes. ${ }^{9-11}$

We examined the effects of the sex hormones oestradiol and testosterone on the early carcinogenic changes expressed in rat liver using a diethylnitrosamine (DEN), 2-acetylaminofluorene (AAF), partial hepatectomy $(\mathrm{PH})$ model of hepatocarcinogenesis. ${ }^{12}$ This model utilises DEN for the initiation step, and dietary $\mathrm{AAF}$ and $\mathrm{PH}$ for the promotion step and has been shown to cause an increased number of preneoplastic liver lesions, including hyperplastic nodules or $\gamma$-glutamyl transferase (GGT) or glutathione-S-transferase placental form (GST-P) positive foci. ${ }^{13-15}$ To exclude the interaction of intrinsic sex hormones, young castrated rats of both sexes were also studied. The eventual changes in preneoplastic liver lesions were judged by histochemical analysis of GST-P ${ }^{16}$ expression. GST-P has been shown to be a very accurate marker enzyme for detection of initiated cells during hepatocarcinogenesis; it is hardly detectable in normal rat liver, but is strongly expressed in preneoplastic liver lesions. ${ }^{17}$ Furthermore, GST-P positive staining of these foci has been shown to correlate with (GGT positivity with the advantage of far less background hepatocyte staining. ${ }^{18} 19$

Materials and methods

PREPARATION OF ANIMALS

Male and female Fischer 344 rats (Japan SLC, Hamamatsu, Japan) three weeks old, weighing 42 (4) g (male) or 36 (3) g (female), were housed in air conditioned animal quarters with lighting from 08.00-20.00, and had unrestricted access to a basal diet (CE-2; Nihon Clea, Tokyo, Japan) and water. Thirty five male rats were divided into six groups (groups 1-6), and 23 female rats were divided into four groups (groups 7-10) (fig 1). Bilateral orchiectomy and ovariectomy were performed in males (groups 5 and 6) and females (groups 9 and 10), respectively, as described previously. ${ }^{20}$ Sham operated males (groups 1-4) and females (groups 7 and 8) were similarly treated, but the testes or ovaries were not removed. Eight experimental groups received the complete carcinogenic treatment (DEN-AAF-PH); rats in the experimental groups (groups 2-6 and 8-10) were initiated with a single intraperitoneal 


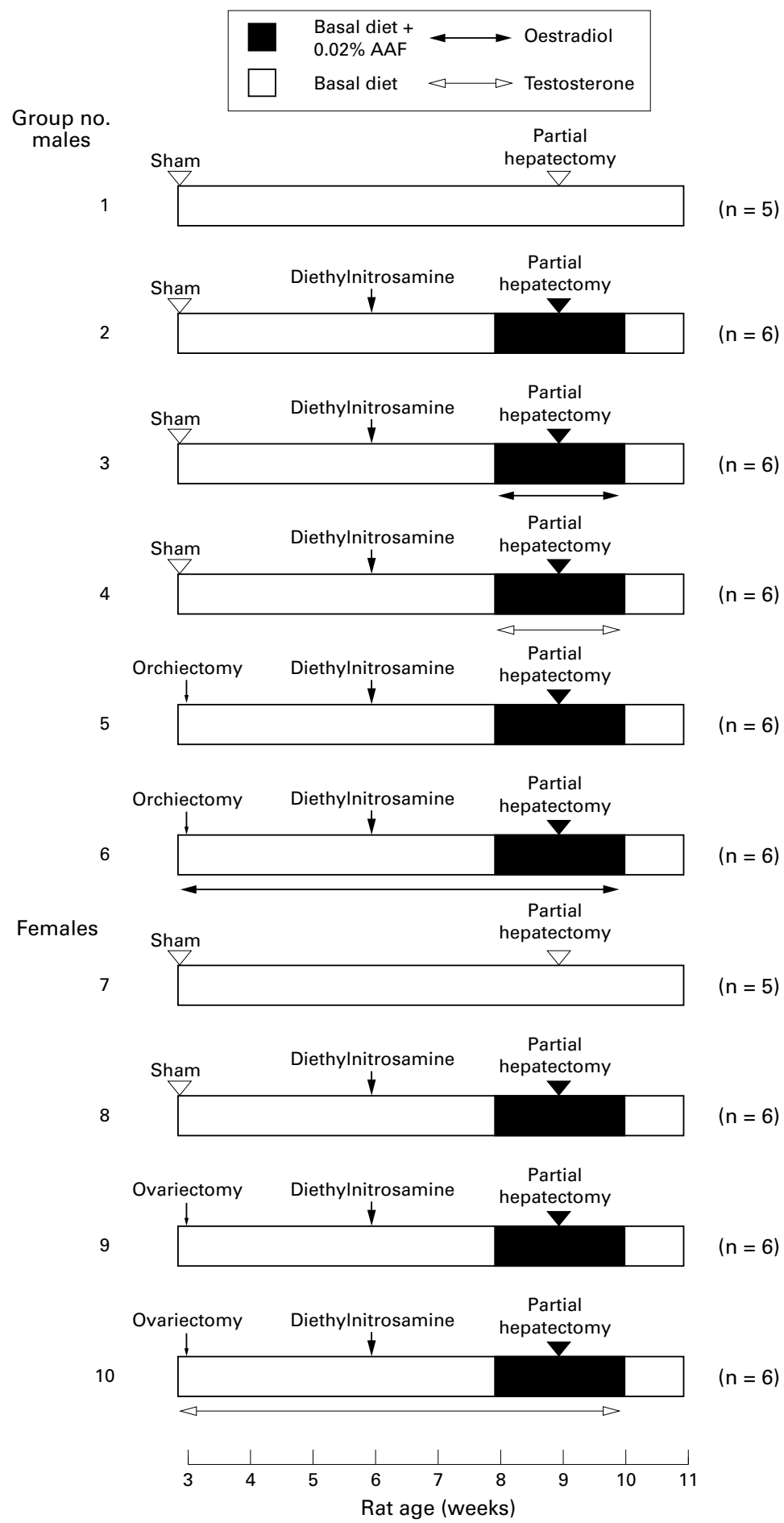

Figure 1 Experimental schedule in DEN-AAF-PH treated rats. Control groups (groups 1 and $7, \mathrm{PH}$ control) were subjected to two thirds $\mathrm{PH}$ only. Sham operated groups were treated with $D E N-A A F-P H$ without (groups 2 and $8, D E N-A A F-P H$ ) or with sex steroid hormones (oestradiol in group 3, DEN-AAF-PH + oestradiol; testosterone in group 4, $D E N-A A F-P H+$ testosterone). Castrated groups were treated without (groups 5 and 9 , castration $+D E N-A A F-P H$ ) or with the opposite sex hormone (oestradiol in group 6 , castration $+D E N-A A F-P H+$ oestradiol replacement; testosterone in group 10 , castration $+D E N-A A F-P H+$ testosterone replacement).

injection of DEN (200 $\mathrm{mg} / \mathrm{kg}$ body weight in $0.9 \% \mathrm{NaCl}$; Sigma, St Louis, Missouri, USA). Two weeks later, they were placed on the basal diet containing $0.02 \%$ AAF (Nakarai Chemical Co., Osaka, Japan) for two weeks to suppress the growth of normal hepatocytes. ${ }^{12}$ The animals were lightly anaesthetised with ether and underwent a standard two thirds $\mathrm{PH}$ at the midpoint of this treatment, to activate the rapid growth of DEN altered hepatocytes not suppressed by AAF. Rats in control groups (groups 1 and 7) were treated with saline, fed the basal diet, and subjected to a two thirds $\mathrm{PH}$. Animals alive one week after the $\mathrm{PH}$ treatment were returned to the basal diet. Oestradiol valerate (Mochida Pharmaceutical Co., Tokyo, Japan) in olive oil was administered intraperitoneally to the orchiectomised three week old males (group 6) at a dose of $3.3 \mathrm{mg} / \mathrm{kg}$ body weight/day for three weeks beginning on the day of the orchiectomy, followed by a dose of $10 \mathrm{mg} / \mathrm{kg}$ body weight twice a week for four weeks. Rats in group 3 received oestradiol (3.3 $\mathrm{mg} / \mathrm{kg}$ body weight/day) for two weeks during the period of AAF feeding. Likewise, testosterone propionate (Teikokuzoki Pharmaceutical Co., Tokyo, Japan) in olive oil was given to the ovariectomised females (group 10) for three weeks after ovariectomy using the same protocol as that described for group 6. Animals in group 4 received two weeks of testosterone (3.3 $\mathrm{mg} / \mathrm{kg}$ body weight/day) injections during the period of AAF feeding. All groups received injections of the same volume of olive oil. All animals were deeply anaesthetised with sodium pentobarbital $(40 \mathrm{mg} / \mathrm{kg}$ body weight, intraperitoneally) and killed after terminal exsanguination two weeks after the PH. Blood samples were drawn from the inferior vena cava for radioimmunoassay analysis of serum oestradiol and testosterone, and liver tissue specimens were taken for light microscopy and immunohistochemistry. The remaining liver tissue was promptly removed and was frozen in liquid nitrogen and stored at $-80^{\circ} \mathrm{C}$ for cytosol preparation for oestrogen and androgen receptor studies. All animals were treated humanely in accordance with the Japanese National Guidelines on animal care and use.

LIGHT MICROSCOPY AND

IMMUNOHISTOCHEMISTRY

The liver specimens were fixed overnight in phosphate buffered formaldehyde, embedded in paraffin wax, and stained with haematoxylin and eosin. Polyclonal antisera to rat GST-P21 (MBL Co., Nagoya, Japan), produced against GST-P purified from hyperplastic nodule bearing rat livers, was determined to be specific for the rat liver GST-P using two dimensional electrophoresis, immunoaffinity column chromatography, and western blot analysis. ${ }^{21}$ The avidin-biotin complex (Vectastain R ABC reagent, Vector Laboratories, Burlingame, California, USA) immunohistochemical method was used with minor modifications. Briefly, tissue block sections were mounted on slides, deparaffinised in xylene, and rehydrated in alcohol. Endogenous peroxidase was blocked with $1 \mathrm{ml}$ of hydrogen peroxide per $100 \mathrm{ml}$ of methanol. Incubation with anti-GST-P antibody was preceded by digestion with $0.1 \mathrm{~g}$ of trypsin in $100 \mathrm{ml}$ of phosphate buffered saline (PBS) at $37^{\circ} \mathrm{C}$ for 30 minutes. The antigenantibody complexes were localised with the use of an ABC-peroxidase-diaminobenzidine (DAB) method. As a negative control to 
confirm the specificity of the anti-GST-P antibody, non-immune rabbit serum was substituted for the antiserum.

The numbers and areas of GST-P positive liver foci over $0.2 \mathrm{~mm}$ in diameter were measured using a microcomputer based image analysis system (Imaging Research Inc., Tokyo, Japan). The number of GST-P positive foci was expressed as number $/ \mathrm{cm}^{2}$ and the area of GST-P positive foci was expressed as area $\left(\mathrm{mm}^{2}\right) / \mathrm{cm}^{2}$.

OESTRADIOL AND TESTOSTERONE

RADIOIMMUNOASSAYS

Serum concentrations of oestradiol and total testosterone were measured using commercial radioimmunoassay kits (CIS Diagnostic, Tokyo, Japan; Japan Diagnostic Product Co., Tokyo, Japan, respectively). The lower limits of detection for the oestradiol and total testosterone assay systems were $1.0 \mathrm{pg} / \mathrm{ml}$ and 0.2 $\mathrm{ng} / \mathrm{ml}$, respectively.

OESTROGEN AND ANDROGEN RECEPTOR ASSAYS Cytosols were prepared as previously described by Iqbal et $a^{22}$ with some modifications. Briefly, the frozen liver tissues were homogenised in two volumes of TGM buffer (10 mM Tris, $1.5 \mathrm{mM}$ EDTA, $1 \mathrm{mM}$ dithiothreitol, 10\% glycerol, and $20 \mathrm{mM}$ sodium molybdate, $\mathrm{pH} 7.4$ ) at $4^{\circ} \mathrm{C}$ using Polytron PCU-2 homogeniser (Kinematica, Switzerland). The homogenate was centrifuged at $10500 \mathrm{~g}$ for one hour at $4^{\circ} \mathrm{C}$. The supernatant was retained as cytosol and treated to remove endogenous steroids with dextran coated charcoal $(0.25 \%$ Norit A, Wako Pure Chemical Industries, Osaka, Japan; 0.025\% Dextran T70, Pharmacia Fine Chemicals AB, Uppsala, Sweden) for two hours at $4^{\circ} \mathrm{C}$. The charcoal was removed by centrifugation at 1200 $g$ for 20 minutes. Cytosol (0.2 ml aliquots) was mixed with $0.2 \mathrm{ml}$ of TE buffer $(10 \mathrm{mM}$ Tris and $1.5 \mathrm{mM}$ EDTA) containing $2.5 \mathrm{nM}$ of $6,7-$ ${ }^{3} \mathrm{H}$-oestradiol (54 Ci/mmol, Radiochemical Centre, Amersham, UK) for the oestrogen receptor or $5 \mathrm{nM}$ of ${ }^{3} \mathrm{H}$-methyltrienelone (R1881) (82 Ci/mmol, DuPont/NEN Research Products, Boston, Massachusetts, USA) and 5 $\mathrm{mM} \beta$-mercaptoethanol for the androgen receptor. Non-specific binding was estimated in parallel experiments by including a 100-fold excess of non-radioactive diethylstilboestrol or R1881. All assay tubes for the oestrogen receptor also contained a 500-fold excess of 2-methoxyoestriol to block the oestrogen binding activity of the oestrogen sulphotransferase. For the androgen receptor, $50 \mathrm{mM}$ triamcinolone acetonide was used to block any contribution of the glucocorticoid receptor to total binding. After incubation for 18 hours at $4^{\circ} \mathrm{C}$, free and bound steroids were separated by treatment with $1 \mathrm{ml}$ of dextran coated charcoal in TED buffer (10 $\mathrm{mM}$ Tris, $1.5 \mathrm{mM}$ EDTA, and $1 \mathrm{mM}$ dithiothreitol, $\mathrm{pH}$ 7.4) for 20 minutes at $4^{\circ} \mathrm{C}$, followed by centrifugation at $1000 \mathrm{~g}$ for 30 minutes at $4^{\circ} \mathrm{C}$, and the radioactivity was determined by liquid scintillation in a Packard Tricarb 3225 spectrophotometer. Data were analysed by Scatchard plots corrected for non-specific binding. ${ }^{23}$ Protein was measured by the method of Lowry et $a l^{4}$ with bovine serum albumin as a standard.

\section{STATISTICAL ANALYSIS}

Data are presented as means (SD) unless otherwise indicated. Means were compared between two groups using a two tailed MannWhitney U test. A p value of less than 0.05 was considered significant.

\section{Results}

BODY AND LIVER WEIGHTS

Table 1 shows the body and liver weights of rats given oestradiol or testosterone. Treatment with DEN-AAF-PH caused a significant decrease in body weight in both males and females as compared with animals treated with $\mathrm{PH}$ alone $(\mathrm{PH}$ control), although liver weights were not significantly affected by the DEN-AAF-PH treatment. The body weight of the DENAAF-PH treated males was significantly lower in animals that underwent orchiectomy as compared with those that did not. In contrast, the body and liver weights of the DEN-AAF-PH treated females were significantly greater in those that underwent ovariectomy than in those that did not. Additional administration of oestradiol further decreased the body and liver weights of both non-castrated and castrated

Table 1 Liver and body weights, serum hormone concentrations, and cytosolic hormone receptor concentrations in DEN-AAF-PH treated rats

\begin{tabular}{|c|c|c|c|c|c|c|}
\hline \multirow[b]{2}{*}{ Group treatment number } & \multicolumn{2}{|l|}{ Weight } & \multicolumn{2}{|c|}{ Serum concentrations } & \multicolumn{2}{|c|}{ Hepatic receptor concentrations } \\
\hline & $\operatorname{Body}(g)$ & Liver $(g)$ & $\begin{array}{l}\text { Oestradiol } \\
(\mathrm{pg} / \mathrm{ml})\end{array}$ & $\begin{array}{l}\text { Testosterone } \\
(\mathrm{ng} / \mathrm{ml})\end{array}$ & $\begin{array}{l}\text { Oestrogen } \\
\text { (fmol/mg protein) }\end{array}$ & Androgen \\
\hline \multicolumn{7}{|l|}{ Males } \\
\hline $1 \mathrm{PH}$ control & $273(4)$ & $9.0(0.8)$ & $59(8)$ & $1.3(0.5)$ & $15.2(2.7)$ & $1.2(0.4)$ \\
\hline 2 DEN-AAF-PH & $220(14) \dagger$ & $9.1(0.9)$ & $43(8) \dagger$ & $1.2(0.5)$ & $11.6(2.0) \dagger$ & $1.4(0.6)$ \\
\hline 3 DEN-AAF-PH + oestradiol & $170(11) \dagger^{\star}$ & $7.0(1.7)$ & $238(137) \dagger^{\star}$ & $0.4(0.1) \dagger$ & $10.8(3.1) \dagger$ & $0.9(0.3)$ \\
\hline 4 DEN-AAF-PH + testosterone & $192(15) \dagger^{\star}$ & $7.6(1.8)$ & $79(11)^{\star}$ & $0.8(0.4)$ & $11.1(3.7)$ & $0.8(0.3)$ \\
\hline 5 Orchiectomy + DEN-AAF-PH & $184(15) \dagger^{\star}$ & $8.4(0.6)$ & $41(10 \dagger)$ & $0.8(0.6)$ & $17.0(4.2)^{\star}$ & $1.4(0.5)$ \\
\hline $\begin{array}{l}6 \text { Orchiectomy + DEN-AAF-PH + oestradiol replacement } \\
\text { Females }\end{array}$ & $148(8) \dagger^{\star} \ddagger$ & $6.9(0.3) \dagger^{\star} \ddagger$ & $147(59) \dagger^{\star} \ddagger$ & $<0.2 \dagger \ddagger$ & $15.6(1.8)^{\star}$ & $0.8(0.3) \ddagger$ \\
\hline $7 \mathrm{PH}$ control & $161(3)$ & $3.9(0.6)$ & $110(8)$ & $<0.2$ & $18.8(4.4)$ & $<0.1$ \\
\hline 8 DEN-AAF-PH & $144(4) \dagger$ & $4.0(1.0)$ & $79(15) \dagger$ & $<0.2$ & $14.9(3.0)$ & $<0.1$ \\
\hline 9 Ovariectomy + DEN-AAF-PH & $153(3) \dagger^{\star}$ & $6.3(0.6)^{\star}$ & $72(21) \dagger$ & $<0.2$ & $140(1.9)$ & $0.7(0.4) \dagger^{\star}$ \\
\hline 10 Ovariectomy + DEN-AAF-PH + testosterone replacement & $160(8)^{\star}$ & $6.9(0.4)^{\star}$ & $40(9) \dagger^{\star} \ddagger$ & $<0.2$ & $14.2(3.0)$ & $1.1(0.5) \dagger^{\star}$ \\
\hline
\end{tabular}

Values are expressed as mean (SD).

${ }^{\star} \mathrm{p}<0.05$ versus corresponding value for DEN-AAF-PH in the same sex group.

$t \mathrm{p}<0.05$ versus corresponding value for $\mathrm{PH}$ control in the same sex group.

$\ddagger \mathrm{p}<0.05$ versus corresponding value for castration + DEN-AAF-PH in the same sex group (two tailed Mann-Whitney U test) 
males. Testosterone administration to the DEN-AAF-PH treated males significantly decreased the body weights, while testosterone administration to the ovariectomised females significantly increased the body and liver
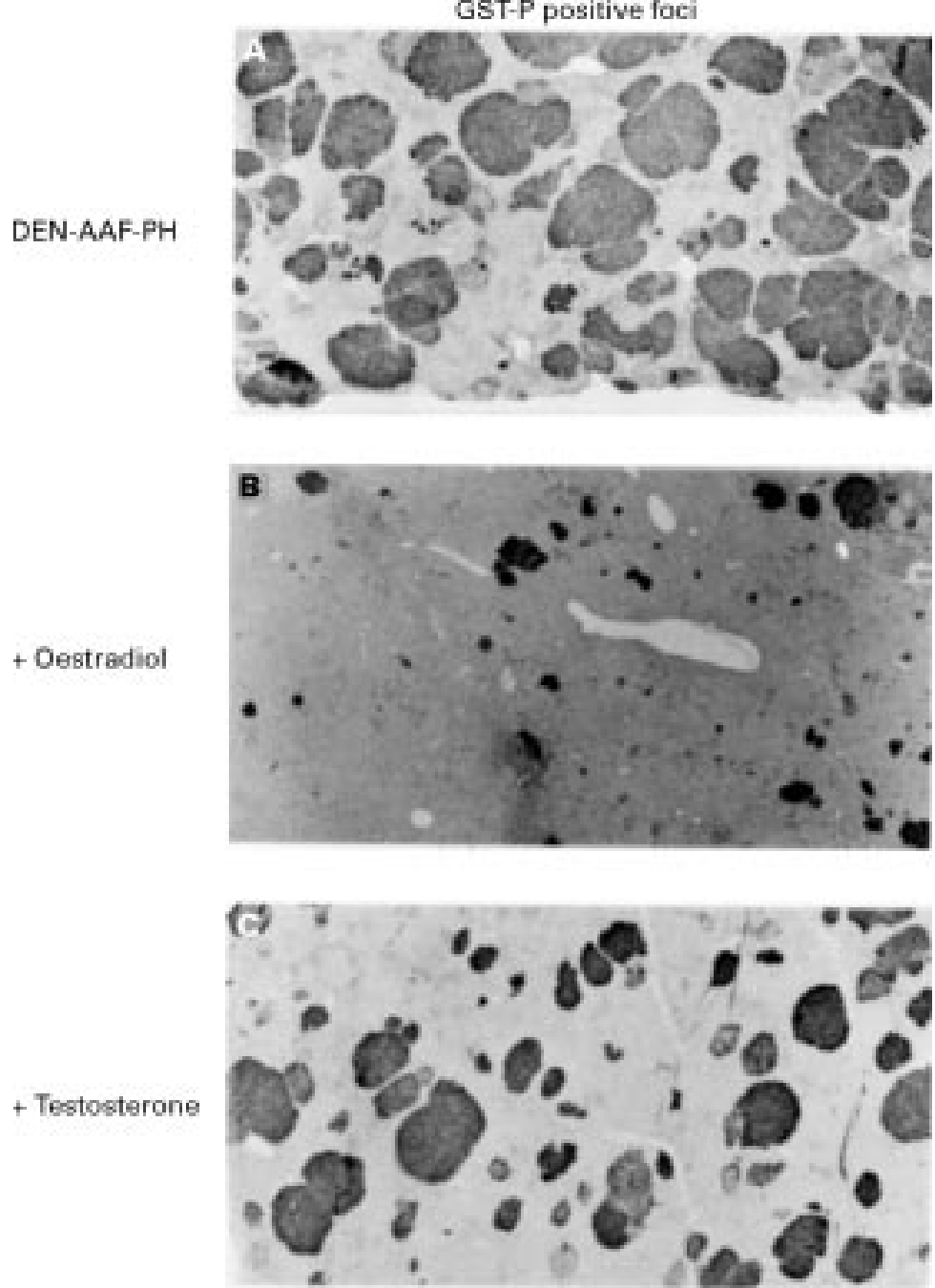

Figure 2 GST-P positive liver foci in non-castrated male rats induced using the $D E N-A A F-P H$ model $(A)$ given oestradiol $(B)$ or testosterone (C). Original magnification $\times 5$. weights. These findings suggest that exogenous oestradiol has a suppressive effect on body and liver weights, and that the weight enhancing effect of exogenous testosterone is at least partly downregulated by oestrogen production in the ovaries and by increased peripheral conversion of androgens and oestrogen precursors into oestrogens.

CHARACTERISTICS OF SEX STEROID HORMONES IN THE DEN-AAF-PH MODEL

Table 1 shows the mean levels of hepatic oestrogen and androgen receptors and serum sex steroid hormones in the DEN-AAF-PH treated rats with or without castration and/or exogenous hormone treatment. The DENAAF-PH treated rats showed diminished levels of the hepatic oestrogen receptor and serum oestradiol, but there was no decline in levels of the hepatic androgen receptor or serum testosterone in male or female rats. Significant differences were found for all values measured in DEN-AAF-PH treated rats as compared with PH controls except for the hepatic oestrogen receptor level in females. Hepatic oestrogen receptor levels in non-castrated DENAAF-PH treated males were significantly lower than those for PH only control animals, but no significant difference was seen between castrated, DEN-AAF-PH treated males, and $\mathrm{PH}$ controls. Castration in females was associated with higher hepatic androgen receptor levels compared with those of non-castrated females, but was not associated with a significant change in the oestrogen receptor levels. Exogenous oestradiol increased the serum oestradiol concentration and decreased the serum testosterone concentration in the DENAAF-PH treated males (both non-castrated and castrated); exogenous oestradiol increased the hepatic oestrogen receptor levels in castrated, but not non-castrated males, and did not significantly affect the hepatic androgen receptor levels. In response to testosterone administration, the serum oestradiol level in the DEN-AAF-PH treated males increased to the $\mathrm{PH}$ control level, and declined in the castrated females. Moreover, exogenous

Females
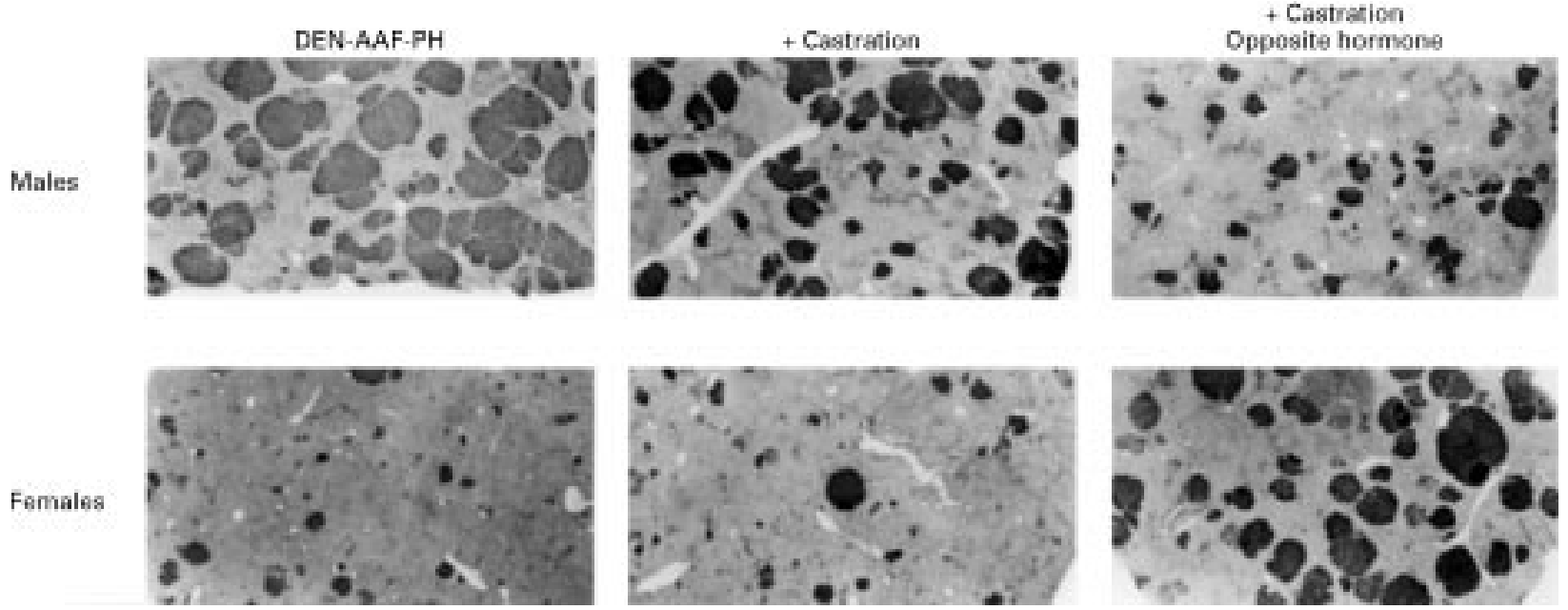

Figure 3 Effect of castration and opposite sex steroid hormone on the development of GST-P positive liver foci in male and female rats induced using the $D E N-A A F-P H$ model. Original magnification $\times 5$. 

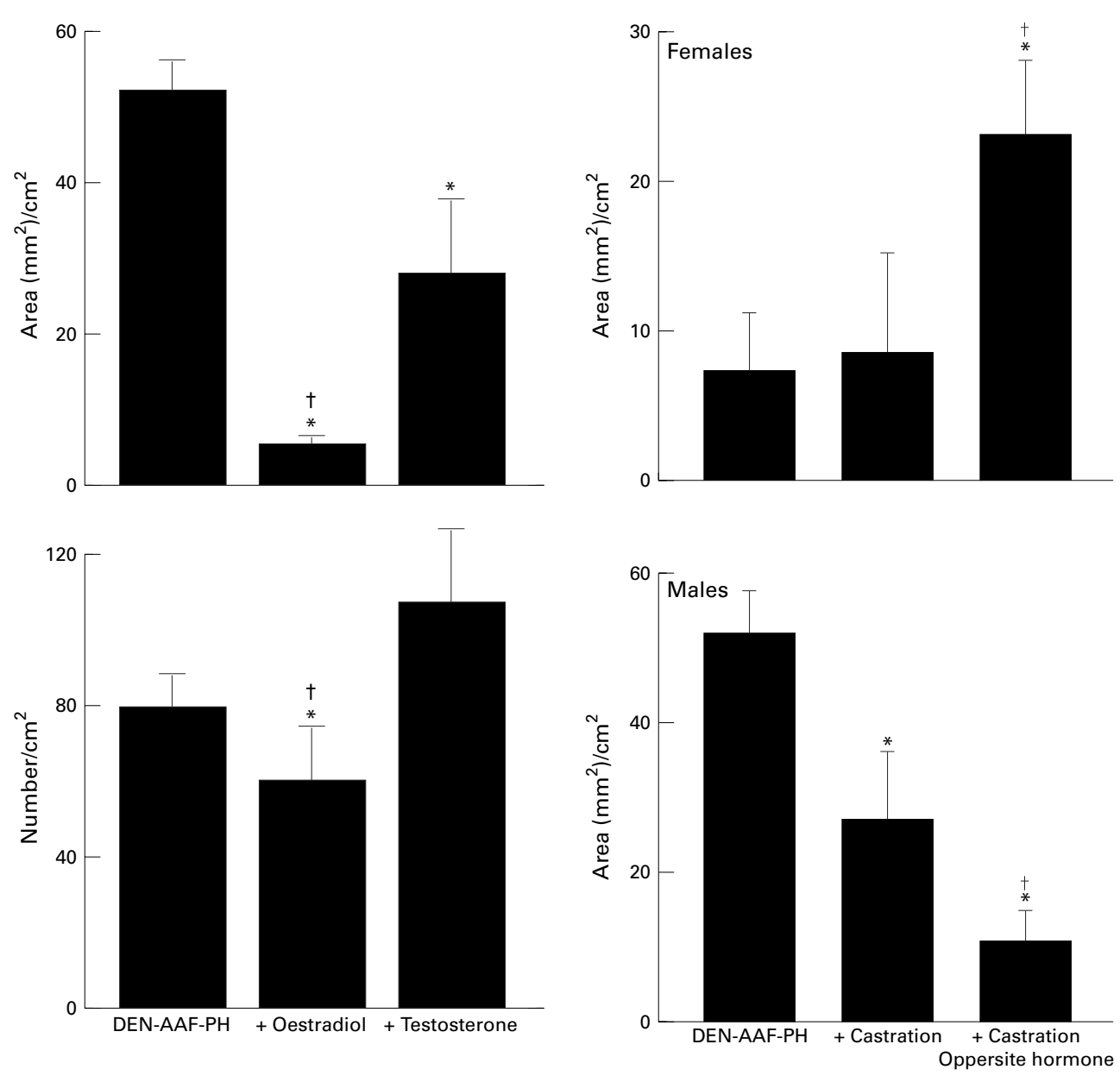

Figure 4 Numbers and areas of GST-P positive liver foci in non-castrated male rats induced using the $D E N-A A F-P H$ model with oestradiol or testosterone. ${ }^{*} p<0.05$ versus corresponding value for $D E N-A A F-P H$ only; $t p<0.05$ versus corresponding value for DEN-AAF-PH + testosterone (two tailed Mann-Whitney $U$ test). Values are mean (SD).

testosterone was associated with an increase in the hepatic androgen receptor levels in the castrated females to the male $\mathrm{PH}$ control values.

\section{GST-P POSITIVE FOCI}

GST-P is present in bile duct epithelial cells but not in hepatocytes, in the livers of normal and $\mathrm{PH}$ control rats of both sexes. ${ }^{22}{ }^{23}$ When male and female rats were treated with DEN-AAF$\mathrm{PH}$, numerous GST-P positive foci in the liver were seen (figs 2 and 3). The area of GST-P positive foci induced in the DEN-AAF-PH treated rats was sevenfold higher in males than in females (figs 3 and 5). Oestradiol administration resulted in a significant decrease in the number $\left(61(14) / \mathrm{cm}^{2}\right)$ and area $\left(4(1) \mathrm{mm}^{2} /\right.$ $\mathrm{cm}^{2}$ ) of GST-P positive foci as compared with DEN-AAF-PH values (81 (6)/ $\mathrm{cm}^{2}$ and 52 (5) $\mathrm{mm}^{2} / \mathrm{cm}^{2}$, respectively) in non-castrated male rats; however, when non-castrated males were given testosterone, GST-P positive foci were reduced in terms of area $\left(29(9) \mathrm{mm}^{2} / \mathrm{cm}^{2}\right)$ but not number (106 (21) $\mathrm{cm}^{2}$ ) (fig 4). In DEN-AAF-PH treated males, the area of GST-P positive foci was reduced in animals that underwent orchiectomy alone (27 (9) $\mathrm{mm}^{2} / \mathrm{cm}^{2}$ ) and in those that underwent orchiec-

Figure 5 Areas of GST-P positive liver foci in male and female rats induced in the DEN-AAF-PH model with castration and opposite sex steroid hormone. ${ }^{*} p<0.05$ versus corresponding value for $D E N-A A F-P H$ only; $t p<0.05$ versus corresponding value for castration + $D E N-A A F-P H$ (two tailed Mann-Whitney $U$ test). Values are mean (SD).

tomy and oestradiol replacement $\left(10\right.$ (3) $\mathrm{mm}^{2} /$ $\mathrm{cm}^{2}$ ) (fig 5). In DEN-AAF-PH treated females, the GST-P positive area was threefold higher in animals that underwent ovariectomy and testosterone replacement, but was not significantly different in animals that underwent ovariectomy only (fig 5). The apparent differences in the effect of exogenous testosterone on noncastrated males compared with castrated females may be due to a feedback effect on oestrogen formation in the ovaries and peripheral organs by the male sex hormone. These findings suggest that oestradiol suppresses the development of GST-P positive liver foci in this model of hepatocarcinogenesis.

\section{Discussion}

In this study we found that oestradiol administration resulted in a significant decrease in the number and area of GST-P positive liver foci in non-castrated male animals that underwent the DEN-AAF-PH hepatocarcinogenic treatment, and that testosterone administration to noncastrated males resulted in an increased serum oestradiol level, and decreased area of GST-P positive foci. In DEN-AAF-PH treated males, treatment with castration only or with castration 
and oestradiol replacement was associated with a significant reduction in the area of GST-P positive foci, and an increase in the oestrogen receptor level. In DEN-AAF-PH treated female rats, the area of GST-P positive foci and the androgen receptor level were significantly greater in animals that underwent ovariectomy and testosterone replacement than in those that did not. These findings suggest that exogenous and endogenous oestradiol can suppress chemical hepatocarcinogenesis, that oestrogen receptors may be involved in the inhibition of malignant transformation of preneoplastic liver cells distinguished as GST-P positive foci, and that androgens and androgen receptors are involved in hepatocarcinogenesis. Moreover, our preliminary study indicated that oestradiol had the ability in a dose dependent manner to reduce the area of GST-P positive foci in noncastrated males (data not shown).

Much controversy exists with respect to the effectiveness of oestrogens as promoters of hepatocarcinogenesis, particularly after induction by chemical carcinogens. ${ }^{25-32}$ Taper $^{25}$ showed that ovariectomised female rats given $17 \mathrm{~b}$-oestradiol phenylpropionate and oestradiol benzoate developed an increased number of transformed hepatic foci and HCC initiated by $\mathrm{N}$-nitrosomorpholine. Cameron et $a l^{26}$ showed that ethinyloestradiol administration enhanced these foci in Fischer rats after exposure to DEN. In intact rats after $\mathrm{PH}$, Yager and Yager ${ }^{27}$ showed that animals fed mestranol and norethynodrel containing diets had greater numbers of transformed foci. These findings are contradictory to our results showing suppression of DEN initiated preneoplastic liver foci by oestradiol. This discrepancy may be a result of differences in the sex steroid compounds and experimental procedures used. In particular, it should be noted that the doses of ethinyloestradiol and mestranol in these studies were 200 times the usual doses found in oral contraceptive steroids. In contrast, studies by others with several hepatic promoters, including phenobarbital, ${ }^{28}$ clofibrate $^{30}$ and ethinyloestradiol ${ }^{31}$ at nonhepatotoxic doses, have shown that following an initial, transient increase in liver growth, continued exposure causes inhibition of basal and/or induced growth. Abanobi et $a l^{28}$ found that while DNA synthesis was stimulated by feeding a hepatotoxic choline devoid diet, simultaneous treatment with phenobarbital was inhibitory. Barbason et $a l^{29}$ and Yager et al ${ }^{31}$ reported that treatment with phenobarbital or ethinyloestradiol inhibited hepatocyte proliferation induced by $\mathrm{PH}$. Yager et $a l^{31}$ also have showed in intact female rats that while ethinyloestradiol increased hepatocyte proliferation during the first seven days of treatment, the basal level of liver growth was dramatically inhibited after 28 and 42 days of ethinyloestradiol treatment. Mishkin et $a l^{32}$ have found that exogenous $17 \mathrm{~b}$-oestradiol exerted inhibitory effects on the growth and malignant transformation of liver foci produced by AAF in male Fischer 344 rats. Moreover, they reported that combined administration of tamoxifen and oestradiol also inhibited liver foci, malignant transformation, and mortality, suggesting that tamoxifen is acting as an oestrogen agonist. ${ }^{33}$ This supports the view that oestrogens suppress hepatocarcinogenesis.

Sex hormones exert their effects on the liver through interaction with specific intracellular receptors. ${ }^{34}$ The oestrogen receptor is well characterised in both rat and human liver. ${ }^{35} 36$ Several groups have shown the presence of oestrogen receptors in HCC specimens as well as in adjacent normal human liver. ${ }^{37-39}$ The data suggested that oestrogen receptor levels were lower in HCC samples than in normal liver, but the differences reported were not significant. ${ }^{38}$ However, it is difficult to correlate or compare the data from these various reports because of the limited numbers of human tumours examined, and the wide range of binding values obtained in each study. In this study, we found cytosolic oestrogen receptors in preneoplastic liver lesions produced by DEN-AAF-PH. The oestrogen receptor level in the preneoplastic liver in male rats was significantly lower than that in control livers treated with $\mathrm{PH}$ only, and was not significantly different from the $\mathrm{PH}$ control level in animals that received oestradiol alone or oestradiol and orchiectomy. Female oestrogen receptor levels were lower, but not significantly, in DEN-AAF-PH treated animals compared with the PH controls, but were not changed with hormone treatments. Recently, Villa et $a l^{40}$ have reported variant oestrogen receptor transcripts lacking the hormone binding domain in cancerous liver tissues, but not in pericancerous or normal liver tissues in men. They suggested that the variant oestrogen receptors lose the dependence on hormone control, and may offer a potential mechanism for the escape of the tumour from hormone control. ${ }^{41}$ These findings and our data implicate oestrogen dependency for anticarcinogenic regulation in hepatocarcinogenesis.

Androgens have been associated with liver disease as well. ${ }^{5-8}$ Most studies ${ }^{42-44}$ involving cytosolic and nuclear androgen receptor levels of HCC samples have suggested increased androgen receptor positivity or androgen receptor levels in HCC as compared with normal liver tissue. These findings are in accordance with our data indicating a significant decrease in serum testosterone levels in noncastrated males after oestradiol administration and a significant increase in hepatic cytosolic androgen receptor levels in females that received castration and testosterone, in association with the development of preneoplastic liver lesions. However, testosterone administration to non-castrated males in this study reduced the area of transformed GST-P positive foci with an increased serum oestradiol level. This could be due to a feedback effect on the hypothalamopituitary axis responsible for oestrogen formation in the testes and peripheral organs by the administered testosterone, suggesting that endogenous oestradiol might be a more important factor involved in the regulation of malignant transformation of preneoplastic liver cells than exogenous testosterone. It remains to be elucidated, however, whether a larger quantity of testosterone than 
that used in this study can inhibit malignant transformation of liver foci, and how hepatic receptor levels and serum levels of sex steroid hormones will respond after administration of sex hormones to non-castrated humans.

The mechanism whereby sex hormones are involved in hepatocarcinogenesis is unknown. However, oestrogen is a strong endogenous antioxidant that inhibits serum and liver lipid peroxide levels. ${ }^{45}$ Our preliminary studies have also shown that oestradiol inhibits lipid peroxidation in rat liver mitochondrial membranes induced by adenosine 5'-diphosphate (ADP) and $\mathrm{Fe}^{2+} \cdot{ }^{46}$ There is increasing evidence that naturally occurring and synthetic antioxidants inhibit liver carcinogenesis in rats. ${ }^{47} 48$ An alternative possibility to account for the sex difference in the growth rate of GST-P positive foci in rats treated with DEN-AAF-PH would be a sexual dimorphism in growth hormone secretion. ${ }^{49} 50$ Blanck et $a l^{49}$ reported that castration of male rats and continuous infusion of growth hormone to males during AAF-PH treatment in the DEN-AAF-PH model decreased the focal growth rate towards that in female rats. All manipulations leading to a "feminised" pattern of growth hormone secretion were characterised by a higher basal serum level of growth hormone than in the normal male. ${ }^{50}$ Although a possible causative role for oxygen radical interactions and growth hormone regulated mitoinhibition during the promotion stage in the present protocol has not been confirmed, such mechanisms merit further consideration.

Recently, our preliminary study using a hepatic fibrosis model induced in male rats by a single dose of dimethylnitrosamine (DMN) has indicated that oestradiol treatment resulted in repaired hepatic fibrosis, whereas treatment with a neutralising antirat oestradiol antibody has been found to enhance fibrogenesis in the DMN model..$^{51}$ We also suggested suppressive effects of oestradiol on DMN induced fibrosis of the liver in non-castrated and castrated rats of both sexes. ${ }^{52}$ In addition to the fibrosuppressive role, the present findings clearly indicate that oestradiol exerts a suppressive effect on hepatocarcinogenesis. Further clarification of the role of sex steroid hormones and their receptors may provide the rationale for new therapies for hormonally responsive liver disease.

The authors thank Dr Masayuki Shono for useful advice regarding the photomicroscopic techniques. This work was supported in part by Grant-in-Aid for Scientific Research No 06670559 from the Ministry of Education, Science and Culture of Japan.

1 Okuda F, Fujimoto I, Hanai A, Urano Y. Changing incidence of hepatocellular carcinoma in Japan. Cancer Res 1987;47:4967-72.

2 Villa E, Baldini GM, Pasquinelli C, et al. Risk factors for hepatocellular carcinoma in Italy: male sex, hepatitis B virus, non-A, non-B infection, alcohol. Cancer 1988;62: 611-5.

3 Johnson PJ, Krasner H, Portmann B, Eddleston ALWF, Williams R. Hepatocellular carcinoma in Great Britain: influence of age, sex, HBsAg status and aetiology of underlying cirrhosis. Gut 1978;19:1022-6.

4 Drinkwater NR. The interaction of genes and hormones in murine hepatocarcinogenesis. In: Cockburn A, Smith L murine hepatocarcinogenesis. In: Cockburn A, Smith L,
eds. Nongenotoxic carcinogenesis. New York: Springereds. Nongenotoxic carci
Verlag, 1994:219-30.

5 Anthony AP. Hepatoma associated with androgenic steroids. Lancet 1975;i:485-6.
6 Mulvihill JJ, Ridolfi FL, Schultz FR, Borzy MS, Haughton PBT. Hepatic adenoma in Fanconi's anemia treated with PBT. Hepatic adenoma in Fanconi's an
oxymetholone. F Pediatr 1975;87:122-4.

7 Meadows AT, Naiman JL, Valdes-Dapena M. Hepatoma associated with androgen therapy for aplastic anemia. $\mathcal{F}$ Pediatr 1974;84:109-10.

8 Erdstein J, Wisebord S, Mishkin SY, et al. The effect of several sex steroid hormones on the growth rate of three Morris hepatoma tumor lines. Hepatology 1989;9:621-4.

9 Schecter J, Ahmad N, Elias K, et al. Oestrogen-induced tumor changes in vasculatures in two strains of rat. $A m \mathcal{F}$ Anat 1987; 179:315-23.

10 Porter LE, Van Thiel DH, Eagon PK. Oestrogens and progestins as tumor inducers. Semin Liver Dis 1987;7:24-31.

11 Porter LE, Elm MS, Van Thiel DH, et al. Hepatic oestrogen receptor

12 Solt D, Farber E. New principle for the analysis of chemical carcinogenesis. Nature 1976;263:701-3.

13 Ito N, Tsuda H, Hasegawa R, et al. Sequential observation of pathomorphologic alterations in preneoplastic lesions during the promoting stage of hepatocarcinogenesis and the development of a short-term test system for hepatopromoters and hepatocarcinogens. Toxicol Pathol 1982;10:3749.

14 Tatematsu M, Hasegawa R, Imaida K, et al. Survey of various chemicals for initiating and promoting activities in a short-term in vivo system based on generation of hyperp.

15 Sato K. Glutathione transferases as markers of preneoplasia and neoplasia. Adv Cancer Res 1990;52:205-55.

16 Ogiso T, Tatematsu M, Tamano S, et al. Comparative effects of carcinogens on the induction of placental glutathione S-transferase-positive liver nodules in a short-term assay and of hepatocellular carcinomas in a long-term assay. and of hepatocellular carcino
Toxicol Pathol 1985;13:257-65.

17 Tatematsu M, Mera Y, Ito N, et al. Relative merits of immunohistochemical demonstrations of placental, A, B and C forms of glutathione S-transferase and histochemical demonstration of $\gamma$-glutamyl transferase as markers of altered foci during liver carcinogenesis in rats. Carcinogenesis 1985; 6:1621-6.

18 Tatematsu M, Mera Y, Inoue T, Satoh K, Sato K, Ito N. Stable phenotypic expression of glutathione S-transferase placental type and unstable phenotypic expression of $\gamma$-glutamyl transferase in rat liver preneoplastic and neoplastic lesions. Carcinogenesis 1988;9:215-20.

19 Satoh K, Kitahara A, Soma Y, Inaba Y, Hayama I, Sato K. Purification, induction and distribution of placental glutathione transferase: a new marker enzyme for preneoglutathione transferase: a new marker enzyme for preneo-
plastic cells in the rat chemical carcinogenesis. Proc Natl Acad Sci USA 1985;82:3964-8.

20 Batchelor JR, Chapman BA. The influence of sex upon the antibody response to an incompatible tumor. Immunology 1965;9:553-7.

21 Sato K, Kitahara A, Satoh K, et al. The placental form of glutathione S-transferase as a new marker protein for preneoplasia in rat chemical hepatocarcinogenesis. Gann 1984;75:199-202.

22 Iqbal MJ, Wilkinson ML, Johnson PJ, et al. Sex steroid receptor proteins in foetal, adult and malignant liver tissue. Br f Cancer 1983;48:791-6.

23 Chamness GC, McGuire WL. Scatchard plots: common errors in correction and interpretation. Steroids 1975;26: 538-40.

24 Lowry $\mathrm{OH}$, Rosebrough NJ, Farr AL, et al. Protein measurement with the Folin phenol reagent. 7 Biol Chem 1951;193:265-75.

25 Taper HS. The effect of $\mathrm{E}_{2}-17$-phenylpropionate and $\mathrm{E}_{2}$ benzoate in N-nitrosomorpholine-induced liver carcinogenesis in ovariectomized female rats. Cancer 1978;42:4627.

26 Cameron RG, Imaida K, Tsuda H, et al. Promotive effects of steroids and bile acids on hepatocarcinogenesis initiated by diethylnitrosamine. Cancer Res 1984;44:2698-703.

27 Yager JD, Yager R. Oral contraceptive steroids as promoters of hepatocarcinogenesis in female Sprague Dawley rats. Cancer Res 1980;40:3680-5.

28 Abanobi SE, Lombardi B, Shinozuka H. Stimulation of DNA synthesis and cell proliferation in the liver of rats fed a choline-devoid diet and their suppression by phenobarbital. Cancer Res 1982;42:412-5.

29 Barbason H, Rassenfosse C, Betz EH. Promotion mechanism of phenobarbital and partial hepatectomy in DENA hepatocarcinogenesis cell kinetics effect. Br f Cancer 1983; hepatocarcin.

30 Tanaka K, Smith PF, Stromberg PC, et al. Studies of early hepatocellular proliferation and peroxisomal proliferation in Sprague-Dawley rats treated with tumorigenic doses of clofibrate. Toxicol Appl Pharmacol 1992;116:71-7.

31 Yager JD, Zurlo J, Sewall CH, et al. Growth stimulation folowed by growth inhibition in livers of female rats treated with ethinyl oestradiol. Carcinogenesis 1994;15:2117-23.

32 Mishkin SY, Farber E, Ho RK, et al. Evidence for the hormone dependency of hepatic hyperplastic nodules: inhibition of malignant transformation after exogenous
17b-oestradiol and tamoxifen. Hepatology 1983;3:308-16.

33 Mishkin SY, Farber E, Ho RK, et al. Tamoxifen alone or in combination with oestradiol-17b inhibits the growth and
malignant transformation of hepatic hyperplastic nodules. marignant transformation of hepatic hype 34 King RJB. Structure and function of steroid receptors. $\mathcal{F}$ 
35 Eagon PK, Fisher SE, Imhoff AF, et al. Oestrogen-binding proteins of male rat liver: influences of hormonal changes. Arch Biochem Biophys 1980;201:486-99.

36 Porter LE, Elm MS, Van Thiel DH, Duga MC, Eagon PK Characterization and quantitation of human hepatic oestrogen receptors. Gastroenterology 1983;84:704-12.

37 Rossini GP, Baldini GM, Villa E, Manenti F. Characterization of oestrogen receptors from human liver. Gastroenterology 1989;96:1102-9.

38 Friedman MA, Demanes DJ, Hoffman PG. Hepatomas: hormone receptors and therapy. Am f Med 1982;73:262366.

39 Eagon PK, Francavilla A, DiLeo A, et al. Quantitation of oestrogen and androgen receptors in hepatocellular carcinoma and adjacent normal human liver. Dig Dis Sci 1991; 36:1303-8.

40 Villa E, Camellini L, Dugani A, et al. Variant oestrogen receptor messenger RNA species detected in human primary

41 Fuqua SAW, Fitzgerald SD, Chamness GC, et al. Variant human breast tumor oestrogen receptor with constitutive transcriptional activity. Cancer Res 1991;51:105-9.

42 Nagasue N, Ito A, Yukaya H, Ogawa Y. Androgen receptors in hepatocellular carcinoma and surrounding parenchyma. Gastroenterology 1985;89:643-7.

43 Ohnishi S, Murakami T, Moriyama T, Mitamura K, Imawari $M$. Androgen and oestrogen receptors in hepatocellular carcinoma and in the surrounding noncancerous liver tissue. Hepatology 1986;6:440-3.
44 Yoshino K, Komura S, Watanabe I, Nakagawa Y, Yagi K. Effect of oestrogens on serum and liver lipid peroxide levels in mice. F Clin Biochem Nutr 1987;3:233-9.

45 Yoshino K, Komura S, Watanabe I, Nakagawa Y, Yagi K. Effect of oestrogens on serum and liver lipid peroxide levels in mice. F Clin Biochem Nutr 1987;3:233-40.

46 Escobar E, Shimizu I, Yasuda M, et al. Inhibition of hepatofibrogenesis by oestradiol [abstract]. Gastroenterology 1997;112(suppl):A1261.

47 Hochetein P, Atallah AS. The nature of oxidants and antioxidant systems in the inhibition of mutation and cancer. Mutat Res 1988;202:363-75.

48 Ames BN. Dietary carcinogens and anticarcinogens: oxygen radicals and degenerative diseases. Science 1983;221:125664.

49 Blanck A, Eriksson LC, Gustafsson J-A, Hallstrom IP. Sexdifferentiated and growth-hormone-regulated mitoinhibition in rat liver during treatment with 2-acetylaminofluorene and partial hepatectomy in the resistant aminofluorene and partial hepatectomy in the

50 Jansson J-O, Ekberg S, Isaksson O, Mode A, Gustafsson J-A. Imprinting of growth hormone secretion, body growth and hepatic steroid metabolism by neonatal testosterone. Endocrinology 1985;115:555-60.

51 Yasuda M, Shimizu I, Horie C, et al. Oestradiol suppresses liver fibrogenesis [abstract]. Gut 1995;37(suppl 2):A78.

52 Mizobuchi Y, Shimizu I, Yasuda M, et al. Suppressive effect of oestradiol on dimethylnitorosamine-induced fibrosis of the liver in normal and castrated rats of both sexes [abstract]. Hepatology 1996;24(suppl):462A 